\title{
Molecular identification of Wolbachia and Sodalis glossinidius in the midgut of Glossina fuscipes quanzensis from the Democratic Republic of Congo
}

Gustave Simo ${ }^{1, *}$, Sartrien Tagueu Kanté ${ }^{1}$, Joule Madinga ${ }^{2,3}$, Ginette Kame ${ }^{4}$, Oumarou Farikou ${ }^{5}$, Gillon Ilombe ${ }^{6}$, Anne Geiger ${ }^{7,8,9}$, Pascal Lutumba ${ }^{6,10}$, and Flobert Njiokou ${ }^{4}$

${ }^{1}$ Molecular Parasitology and Entomology Unit, Department of Biochemistry, Faculty of Science, University of Dschang, PO Box 67, Dschang, Cameroon

${ }^{2}$ Institute of Health and Society, Université Catholique de Louvain, Clos Chapelle-aux-Champs 30, 1200 Woluwe-Saint-Lambert, Brussels, Belgium

${ }^{3}$ Department of Biomedical Sciences, Institute of Tropical Medicine, Nationalestraat 155, 2000, Antwerp, Belgium

${ }^{4}$ Department of Animal Biology and Physiology, Faculty of Science, University of Yaoundé I, PO Box 812 Yaoundé, Cameroon

${ }^{5}$ Mission Spéciale d'Eradication des Glossines, Division Régionale Tsé-Tsé Adamaoua, PO Box 263 Ngaoundéré, Cameroon

${ }^{6}$ Institut national de recherche biomédicale Kinshasa, Avenue de la démocratie N5345, Gombe, Kinshasa, Democratic Republic of Congo

7 UMR 177, IRD-CIRAD, CIRAD TA A-17/G, Campus International de Baillarguet, Montpellier Cedex 5, France

${ }^{8}$ Center for Research on Filariasis and other Tropical Diseases (CRFILMT), PO Box 5797 Yaoundé, Cameroon

${ }^{9}$ University of Yaoundé I, Faculty of Science, PO Box 812, Yaoundé, Cameroon

${ }^{10}$ Department of Tropical Medicine, University of Kinshasa, B.P. 127 Kinshasa XI, Democratic Republic of Congo

Received 13 September 2018, Accepted 23 January 2019, Published online 7 February 2019

\begin{abstract}
During the last 30 years, investigations on the microbiome of different tsetse species have generated substantial data on the bacterial flora of these cyclical vectors of African trypanosomes, with the overarching goal of improving the control of trypanosomiases. It is in this context that the presence of Wolbachia and Sodalis glossinidius was studied in wild populations of Glossina fuscipes quanzensis from the Democratic Republic of Congo. Tsetse flies were captured with pyramidal traps. Of the 700 Glossina f. quanzensis captured, 360 were dissected and their midguts collected and analyzed. Sodalis glossinidius and Wolbachia were identified by PCR. The Wolbachia-positive samples were genetically characterized with five molecular markers. PCR revealed $84.78 \%$ and $15.55 \%$ midguts infected by Wolbachia and S. glossinidius, respectively. The infection rates varied according to capture sites. Of the five molecular markers used to characterize Wolbachia, only the fructose bis-phosphate aldolase gene was amplified for about $60 \%$ of midguts previously found with Wolbachia infections. The sequencing results confirmed the presence of Wolbachia and revealed the presence of $S$. glossinidius in the midgut of Glossina f. quanzensis. A low level of midguts were naturally co-infected by both bacteria. The data generated in this study open a framework for investigations aimed at understanding the contribution of these symbiotic microorganisms to the vectorial competence of Glossina fuscipes quanzensis.
\end{abstract}

Key words: Glossina fuscipes quanzensis, Wolbachia, Sodalis glossinidius, Democratic Republic of Congo, PCR.

Résumé - Identification moléculaire de Wolbachia et Sodalis glossinidius dans l'intestin moyen de Glossina fuscipes quanzensis de la République Démocratique du Congo. Au cours des 30 dernières années, les recherches sur le microbiome de différentes espèces de glossines ont généré des données substantielles sur la flore bactérienne de ces vecteurs cycliques des trypanosomes africains, l'objectif principal étant d'améliorer le contrôle des trypanosomiases. C'est dans cette optique que la présence de Wolbachia et Sodalis glossinidius a été étudiée dans des populations sauvages de Glossina fuscipes quanzensis de la République démocratique du Congo. Les glossines ont été capturées avec des pièges pyramidaux. Parmi les 700 Glossina $f$. quanzensis capturés, 360 ont été disséqués et leur estomac récupéré et analysé. Sodalis glossinidius et Wolbachia ont été identifiés par PCR. Les échantillons positifs pour Wolbachia ont été génétiquement caractérisés avec cinq marqueurs moléculaires. La PCR a révélé que $84,78 \%$ et $15,55 \%$ de l'intestin moyen étaient respectivement infectés par Wolbachia et S. glossinidius. Les taux d'infection variaient selon les sites de capture. Sur les cinq marqueurs moléculaires utilisés pour caractériser Wolbachia, seul le gène de la fructose bis-phosphate aldolase a été amplifié pour environ $60 \%$ des intestins

*Corresponding author: gsimoca@yahoo.fr

This is an Open Access article distributed under the terms of the Creative Commons Attribution License (http://creativecommons.org/licenses/by/4.0), which permits unrestricted use, distribution, and reproduction in any medium, provided the original work is properly cited. 
moyens précédemment identifiés porteurs de Wolbachia. Les résultats du séquençage ont confirmé la présence de Wolbachia et ont révélé la présence de S. glossinidius dans l'intestin moyen de Glossina f. quanzensis. Un faible taux des intestins moyens était naturellement co-infecté par les deux bactéries. Les données de cette étude ouvrent un cadre pour des recherches visant à comprendre la contribution de ces microorganismes symbiotiques sur la compétence vectorielle de Glossina fuscipes quanzensis.

\section{Introduction}

Human African trypanosomiasis (HAT), also known as sleeping sickness, is caused by protozoan parasites of the genus Trypanosoma. The trypanosomes responsible for HAT belong to the Trypanosoma brucei species complex which is classically subdivided into three subspecies: Trypanosoma brucei $(T . b$. gambiense, responsible for the chronic form of HAT in West and Central Africa, T. $b$. rhodesiense, responsible for the acute form in East and Southern Africa, and T. b. brucei which is pathogenic in animals but not in humans [28]. Apart from the latter subspecies, other pathogenic trypanosomes such as Trypanosoma congolense and Trypanosoma vivax cause African animal trypanosomiasis (AAT) or nagana.

Human African trypanosomiasis is an important public health problem in sub-Saharan Africa. On the basis of HATrelated mortality, HAT has been ranked ninth out of 25 human infectious and parasitic diseases in Africa [21, 47]. Efforts undertaken to control HAT during the last few decades brought the disease under control and led to its inclusion in the WHO "roadmap for eradication, elimination and control of neglected tropical diseases", with a target set to eliminate HAT as a public health problem by 2020 [49]. To achieve this goal, sustainable control and surveillance measures must be developed to ensure complete interruption of disease transmission. In this light, alternative vector control using genetic engineering to generate insects capable of blocking the biological and cyclical transmission of the parasite is becoming an area of new investigation [41]. As a vector-borne disease, complete elimination of tsetse could stop the cyclical transmission of African trypanosomiases. Elimination has been achieved on Unguja Island in Zanzibar [44]; islands often have the advantage of limited tsetse species and also more importantly a lower chance of reinvasion. This seems unrealistic within mainland Africa where environmental and ecological conditions change considerably between biotopes and where several tsetse species coexist in the same biotope. In this context, the development of methods aimed at reducing vectorial competence of tsetse is becoming particularly important. Factors such as the tsetse species, the genetic variability within a given species, and the presence of symbiotic microorganisms seem to regulate vectorial competence of tsetse.

Tsetse flies harbor a variety of microorganisms including Wigglesworthia glossinidia, Sodalis glossinidius and Wolbachia spp. [3, 4, 23]. Wigglesworthia glossinidia is an obligate mutualist bacteria found in all tsetse species. It is essential for adult host fertility and for proper immune maturation $[37,46]$. Sodalis glossinidius is a secondary symbiont which seems to promote midgut establishment of trypanosomes through complex biochemical mechanisms [11, 24, 48]. The third symbiont known as Wolbachia is trans-ovarially transmitted between different generations of tsetse flies. To enhance its transmission and its survival, Wolbachia has developed various mechanisms to alter host reproduction. One of its most common reproductive distortions is the cytoplasmic incompatibility that induces embryonic death due to disruptions in early fertilization events, as previously described in G. morsitans morsitans $[6,29]$. Beside these well-known symbiotic microorganisms, other bacteria including Bacillus subtilis, Serratia marcescens and Spiroplasma [15,33] were recently identified as new symbionts by DNA-based methods [15].

To better understand the biological role of symbiotic microorganisms in the vector competence of tsetse flies, investigations have been undertaken to improve our knowledge on the prevalence of $S$. glossinidius and Wolbachia in different tsetse species from various geographical areas [16, 20]. In tsetse of the fuscipes species, the first studies reported no Wolbachia infection, while other investigations revealed infections in some tsetse subspecies like Glossina fuscipes fuscipes [10, 16, 43]. Despite these contrasting results, no published data are available on the symbiotic microorganisms in Glossina fuscipes quanzensis. However, this tsetse species transmits African trypanosomes in the Republic of Congo and the Democratic Republic of Congo (DRC) where the highest number of HAT cases is reported [18]. In the current elimination context, investigations aiming to generate data on the infection rates of S. glossinidius and Wolbachia in G. f. quanzensis could provide baseline data to understand the vector competence of this tsetse species.

This study aimed to improve our knowledge on the symbiotic association between tsetse flies and its bacteria flora by using molecular tools to detect natural infections by Wolbachia and $S$. glossinidius in the midgut of $G$. $f$. quanzensis caught in the DRC.

\section{Materials and methods}

\section{Study areas}

Tsetse flies were captured in seven active HAT foci situated in three provinces (Bandundu, Eastern Kasaï and Kinshasa) of the DRC (Fig. 1).

In Bandundu province, tsetse flies were captured in Ekubi 2 (S04.55558; ${ }^{\circ} 019.24772^{\circ}$ ), a village lying alongside the Kamtsa river which flows through a wide forest gallery. The vegetation of Ekubi 2 is predominantly characterized by bushy forest and the climate type is sub-equatorial. The primary means of subsistence for inhabitants is agriculture, fishing, fruit picking, hunting and small-scale animal husbandry.

In Eastern Kasaï province, tsetse flies were captured in five villages: Bena Mungelu (S06.03023; E023.79057 ${ }^{\circ}$ ), Kabengele (S06.03094 ${ }^{\circ}$; E023.78581 ${ }^{\circ}$ ), Kabala (S05.97876 ${ }^{\circ}$; E023.76724 ${ }^{\circ}$, Bakwanseke (S06.09524 ${ }^{\circ}$; E023.82041 ${ }^{\circ}$ ) and 


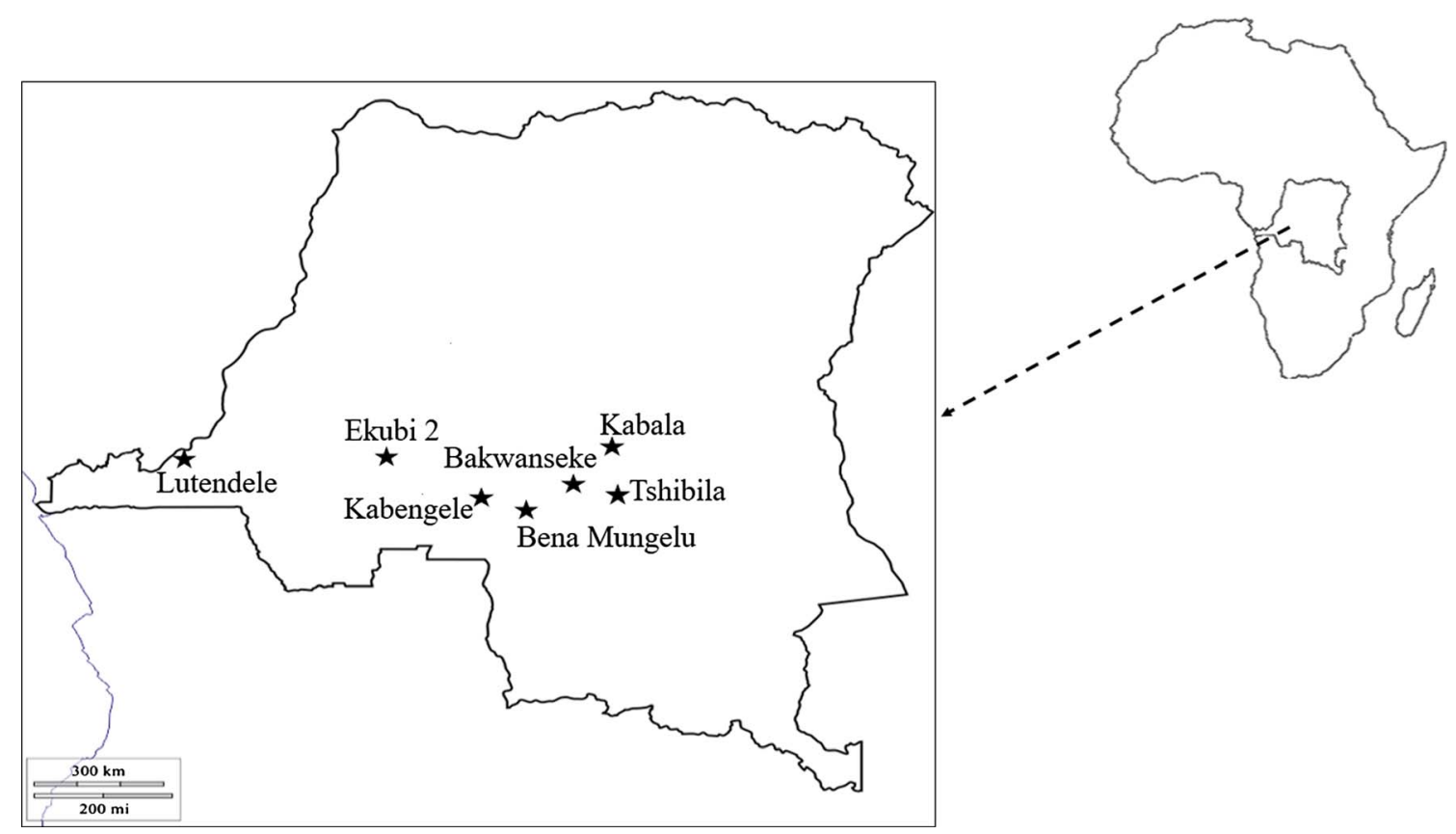

Figure 1. Map showing areas where tsetse flies were caught (stars).

Tshibila (S06.06129 ${ }^{\circ}$ E023.80552 ${ }^{\circ}$ ). These villages share the same climatic, cultural and socio-economic characteristics. They lie in a shrubby savannah, with small streams that are all tributaries of the Lubilanji River. Farming and domestic livestock production represent the main economic activities for the inhabitants of these villages.

Kinshasa (S04.54011 ${ }^{\circ}$; E019.22098 $)$ is the capital of the DRC and lies along the Congo River. It is also the capital of "Kinshasa Province" with the urban area covering $4.5 \%$ of the $9965 \mathrm{~km}^{2}$ of the whole province. One part of the city lies on an alluvial plain up to the hills of the southern, western, and eastern sites. Kinshasa has a significant hydrographical network that crosses the mountains. In the periphery, the vegetation includes steppes, semi-deciduous and riverine forest islands, and wooded and grassy savannah [27]. It has an Atlantic littoral climate with low rainfall, low temperature, minimum sunshine, and maximum cloud mass. With a population of more than 8 million inhabitants, the association of unemployment and food precariousness has led many people to produce their own food in the suburban and rural areas of Kinshasa. Tsetse flies were captured in Lutendele, one of the suburban areas of Kinshasa.

\section{Trapping and dissection of tsetse flies}

Two entomological surveys were undertaken in October 2009 and June 2010. During each survey, pyramidal traps [26] were set up for four consecutive days. The geographical coordinates of each trap were recorded using a global positioning system (GPS). Tsetse flies were collected once a day. All collected flies were morphologically identified, counted and sorted into teneral and non-teneral flies as described by Laveissière et al. [32]. Some of the live flies were randomly selected and dissected in a drop of $0.9 \%$ saline solution using a stereo-microscope. After dissection, the midgut of each fly was collected and preserved in a microtube containing $95^{\circ}$ ethanol. Each microtube was kept at room temperature in the field, and later at $-20{ }^{\circ} \mathrm{C}$ in the laboratory. Between two dissections, cross-contaminations were prevented by cleaning the dissecting instruments in a solution of sodium hydroxide $(0.1 \mathrm{M})$ and then, in distilled water.

\section{DNA extraction}

DNA was extracted from each tsetse fly midgut using the Cetyl trimethyl ammonium bromide (CTAB) method as described by Navajas et al. [36]. Briefly, the alcohol used to preserve midgut tissue was evaporated by incubating the opened microtube containing tsetse fly midgut at $80{ }^{\circ} \mathrm{C}$ in an oven for about one hour. Thereafter, midgut tissues were disrupted with a pestle in CTAB buffer (CTAB 2\%; 1 M Tris, $\mathrm{pH} 8 ; 0.5 \mathrm{M}$ EDTA, $\mathrm{pH} 8 ; 5 \mathrm{M} \mathrm{NaCl}$ ). The disrupted tissues were incubated at $60{ }^{\circ} \mathrm{C}$ for $30 \mathrm{~min}$ before addition of chloroform/isoamylic alcohol mixture $(24 / 1 ; \mathrm{V} / \mathrm{V})$. The DNA was precipitated by addition of isopropanol $(\mathrm{V} / \mathrm{V})$ and centrifugation at 13,000 rpm for $15 \mathrm{~min}$. The DNA pellets were washed twice with $70 \%$ cool ethanol and then dried at room temperature. The DNA pellets were finally re-suspended in $30 \mu \mathrm{L}$ of sterile water and stored at $-20{ }^{\circ} \mathrm{C}$ until use.

\section{Molecular identification of S. glossinidius}

The presence of $S$. glossinidius was determined by amplifying a specific DNA fragment with pSG2 primers as described by Darby et al. [12]. Each PCR reaction was carried out in a DNA thermal cycler (TECHNE TC 4000). The amplification reactions were performed in a final volume of $15 \mu \mathrm{L}$ containing $3 \mu \mathrm{L}$ of DNA extract, $1.5 \mu \mathrm{L}$ of $10 \mathrm{X}$ PCR reaction buffer, 
$2 \mathrm{mM}$ of $\mathrm{MgCl}_{2}, 20$ picomoles of each primer (F1: 5'TGAAGTTGGGAATGTCG-3' R1: 5'-AGTTGTAGCACAGCGTGTA-3'), $200 \mathrm{mM}$ of each dNTP and 0.3 unit of Taq DNA polymerase. The amplification program began with a denaturation step at $94{ }^{\circ} \mathrm{C}$ for 3 min followed by 45 amplification cycles; each cycle containing a denaturation step at $94{ }^{\circ} \mathrm{C}$ for $30 \mathrm{~s}$, an annealing step at $51^{\circ} \mathrm{C}$ for $45 \mathrm{~s}$, and an extension step at $72{ }^{\circ} \mathrm{C}$ for one minute followed by a final extension at $72{ }^{\circ} \mathrm{C}$ for $5 \mathrm{~min}$.

After PCR amplification was completed, $10 \mu \mathrm{L}$ of amplified products were analyzed by electrophoresis on a $2 \%$ agarose gel containing ethidium bromide. At the end of each electrophoresis, the gel was visualized under UV light and a picture of each gel was taken.

\section{Molecular identification of Wolbachia}

The identification of Wolbachia was performed using primers pairs wsp $F_{1}$ (GTCCAATARSTGATGARGAAAC) and wsp $\mathrm{R}_{1}$ (CYGCACCAAYAGYRCTRTAAA), as described by Baldo et al. [7]. These primers amplify a 513 bp DNA fragment of Wolbachia surface protein gene. The amplification reactions were performed in a final volume of $15 \mu \mathrm{L}$ containing $3 \mu \mathrm{L}$ of DNA extract, $1.5 \mu \mathrm{L}$ of $10 \mathrm{X}$ PCR reaction buffer, $2 \mathrm{mM}$ of $\mathrm{MgCl}_{2}, 20$ picomoles of each primer, $200 \mathrm{mM}$ of each $\mathrm{dNTP}$ and 0.3 units of Taq DNA polymerase. The amplification program started with a denaturation step at $94{ }^{\circ} \mathrm{C}$ for $3 \mathrm{~min}$ followed by 37 amplification cycles; each cycle containing a denaturation step at $94{ }^{\circ} \mathrm{C}$ for $30 \mathrm{~s}$, an annealing step at $53{ }^{\circ} \mathrm{C}$ for $30 \mathrm{~s}$, and an extension step at $72{ }^{\circ} \mathrm{C}$ for one min followed by a final extension at $72{ }^{\circ} \mathrm{C}$ for $5 \mathrm{~min}$.

Ten micro-liters of amplified products were analyzed by electrophoresis on $2 \%$ agarose gel containing ethidium bromide. Each gel was visualized under UV light and then photographed. All positive samples for Wolbachia were subsequently genotyped with five polymorphic genes.

\section{Multi Locus Sequences Typing (MLST) of Wolbachia sp.}

For the genotyping, five genes including gat B, $\operatorname{cox} A, h c p A$, $f b p A$ and $f t s Z$ were analyzed. Each of these genes was amplified with the primers (Table S1) previously described by Baldo et al. [7]. For each gene, PCR reactions were performed as described by Doudoumis et al. [16]. Each PCR reaction was carried out in a final volume of $25 \mu \mathrm{L}$ containing $2.5 \mu \mathrm{L}$ of $10 \mathrm{X}$ PCR reaction buffer, $2 \mathrm{mM}$ of $\mathrm{MgCl}_{2}, 200 \mathrm{mM}$ of each dNTP, 15 picomoles of each primer, 0.3 units of Taq DNA polymerase (Qiagen $5 \mathrm{U} / \mu \mathrm{L}$ ), and $5 \mu \mathrm{L}$ of DNA extract. The amplification programs consisted of a denaturation step at $94{ }^{\circ} \mathrm{C}$ for $5 \mathrm{~min}$, followed by 36 cycles. Each of these cycles contained a denaturation step at $94{ }^{\circ} \mathrm{C}$ for $30 \mathrm{~s}$, an annealing step of $30 \mathrm{~s}$ at $52^{\circ} \mathrm{C}$ for $f t s Z, 54^{\circ} \mathrm{C}$ for gat $B, 55^{\circ} \mathrm{C}$ for $\operatorname{cox} A, 56^{\circ} \mathrm{C}$ for $h c p A$, and $58{ }^{\circ} \mathrm{C}$ for $f b p A$, and an elongation step at $72{ }^{\circ} \mathrm{C}$ for one minute. All reactions were followed by a final extension step at $72{ }^{\circ} \mathrm{C}$ for $10 \mathrm{~min}$.

To resolve the PCR products, $10 \mu \mathrm{L}$ of amplified products were analyzed by electrophoresis on $2 \%$ agarose gel containing ethidium bromide. Each gel was visualized under UV light and then photographed. Some positive samples were subsequently purified and sent for sequencing.

\section{Sequencing of fbpA fragments}

To confirm the presence of different bacteria species, the amplified fragments of fbpA from Wolbachia, were sequenced. For this sequencing, three samples were randomly selected. For each sample, two amplicons (two replicates) were sequenced. Before the sequencing, PCR products of the selected samples were purified from agarose gel with the GeneJet PCR purification kit (Qiagen). The sequencing reactions were performed by a commercial company (GATC Biotech AG, Germany). Sequences were obtained by long reads from both ends. The complete sequence of fbpA fragment was generated by aligning the long reads from both ends using Codon Code Aligner sequence assembler 3.7.1 software. Each complete sequence of the amplified fbpA fragment was blasted against fbpA sequences of Wolbachia strains available in GenBank [35, 50]. The blast was done using the BLASTN 2.6.0+ program of the NCBI (https://blast.ncbi.nlm.nih.gov/ blast.cgi).

\section{Statistical analysis}

Statistical analyses were performed using R 3.5.1 [39] Core Team software (R: R Core Team 2018, Vienna, Austria). The frequencies of $S$. glossinidius and Wolbachia infections were presented as proportions with $95 \%$ confidence intervals (CIs). Fisher's exact test in R 3.5.1 2018 Core Team software was used to compare $S$. glossinidius and Wolbachia infection rates between villages. The difference was considered significant when the $p$-value was lower than 0.05 .

\section{Ethics statement}

This study was carried out following the recommendations contained in the Guide for the Care and Use of Animals of the Molecular Parasitology Unit, Department of Biochemistry, University of Dschang.

\section{Results \\ Entomological surveys}

During the entomological surveys, 102 pyramidal traps were set up in different villages and a total of 700 tsetse flies, including 155 teneral $(22.1 \%)$ and 545 non-teneral flies (77.9\%), all belonging to G. f. quanzensis were collected (Table 1). In different villages, the number of flies varied as follows: 3 at Kabengele, 7 at Tshibila, 10 at Bakwanseke, 16 at Kabala, 203 at Ekubi 2, 222 at Lutendele, and 239 at Bena Mungelu. Due to financial constraints, only $51.4 \%$ (360/700) of live tsetse flies were randomly selected, dissected and their midguts preserved for molecular analyses. In all, 360 midguts were subjected to the identification of $S$. glossinidius while, for the same constraints mentioned above, a subset of 184 midguts were subjected to molecular detection of Wolbachia. 
Table 1. Results of entomological surveys.

\begin{tabular}{lccccc}
\hline Villages & No. traps & No. captured flies & ADT & No. teneral flies (\%) & No. dissected flies \\
\hline Bakwanseke & 10 & 10 & 0.25 & 0 & 6 \\
Bena Mungelu & 17 & 239 & 3.51 & $70(29.29)$ & 226 \\
Ekubi 2 & 14 & 203 & 3.63 & $59(29.06)$ & 56 \\
Kabala & 10 & 16 & 0.4 & $6(37.5)$ & 14 \\
Kabengele & 8 & 3 & 0.09 & 0 & 2 \\
Lutendele & 37 & 7 & 1.5 & $20(9.01)$ & 49 \\
Tshibila & 6 & 700 & 0.29 & 0 & 7 \\
Total & 102 & 1.72 & $155(22.14)$ & 360 \\
\hline
\end{tabular}

No.: Number of; ADT: Apparent density per trap per day; (\%): Percentage of teneral flies.

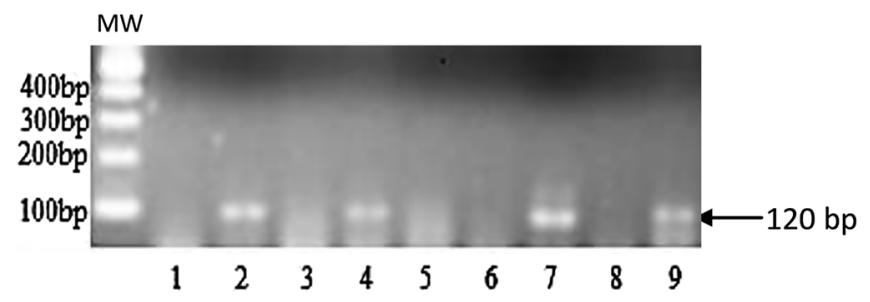

Figure 2. Agarose gel showing the DNA profile resulting from the molecular identification of $S$. glossinidius using pSG2 primers. Lane 1: negative control; lane 9: positive control; lanes 2, 4 and 7: samples positive for S. glossinidius; Lane 3, 5, 6 and 8: samples negative for $S$. glossinidius. MW: 100 bp DNA ladder.

\section{Sodalis glossinidius infection rate}

Figure 2 shows a representative agarose gel illustrating the $120 \mathrm{bp}$ fragment resulting from the amplification of the PSG gene of $S$. glossinidius. Of the 360 midguts that were investigated for the presence of $S$. glossinidius, 56 were found with $S$. glossinidius infections, yielding an overall infection rate of $15.56 \%$. The highest infection rate was observed at Tshibila (42.86\%) followed by Lutendele $(22.45 \%)$ and Bakwanseke (16.67\%). The lowest infection rate of $7.14 \%$ was observed at Ekubi 2 and Kabala. The infection rates reported at Kabala, Kabengele, Tshibila and Bakwanseke must be considered with caution because fewer than 15 tsetse flies were analyzed in each of these villages. Despite the variations observed in the infection rates of $S$. glossinidius, no significant difference $(P=0.2002)$ was observed between villages (Table 2$)$. This difference remains not significant $(P=0.1018)$ even with the subset of 184 samples that were subjected to the molecular identification of Wolbachia (Table 3).

\section{Infection rate of Wolbachia}

Of the 360 midguts collected during this study, 184 were randomly selected and investigated for the presence of Wolbachia. Figure 3 shows a representative agarose gel illustrating the amplification of a Wolbachia surface protein DNA fragment of $513 \mathrm{bp}$, which is specific to Wolbachia. Of 184 midguts analyzed in this study, $156(84.78 \%)$ were found to be positive for Wolbachia infections (Table 3). No sample from Lutendele revealed midgut infection of Wolbachia. All samples from Kabala, Tshibila and Kabengele hosted Wolbachia. The infection rate reported in each of these three villages must be considered with caution because the sample size was very low with fewer than 15 midguts analyzed in each of these villages. Despite the variations observed in the Wolbachia infection rates, their comparison revealed no significant difference $(P=0.9967)$ between villages (Table 3$)$.

\section{Genetic characterization of Wolbachia sp.}

Of the 156 midguts positive for Wolbachia infections, a DNA fragment corresponding to the gene coding for the fructose bisphosphate aldolase (fbpA) was amplified in $93(60 \%)$ of them (Table 4). The amplification rate varied according to villages. The highest amplification rate was observed at Bakwanseke (100\%) followed by Bena Mungelu (70.27\%) (Table 4). To confirm that the amplified fragments of fbpA belonged to Wolbachia, six amplicons from three tsetse flies were sequenced. The sequences were subsequently compared to those available in the database. The sequencing revealed fragments ranging from 490 to $498 \mathrm{bp}$ (Table S2). The blast of fbpA sequences with those of other strains available in GenBank revealed more than $90 \%$ identity with sequences of Wolbachia sp. wRi, (complete genome with accession number: CP001391.1), Wolbachia endosymbiont of Drosophila simulans wHa (complete genome with accession number: CP003884.1), and Wolbachia endosymbiont of Hylaeus variegatus isolate HVa (complete genome with accession numbers: KP183278.1 and KX843420.1) (Table S2). No difference was observed between the sequences and sizes of fragments originating from the same tsetse fly. However, some slight differences were observed between Wolbachia sequences coming from different tsetse flies. For the other selected genes (coxA, ftsZ, gatB and hcpA), no amplification was observed for all the 156 midguts reported with Wolbachia infections.

\section{Co-infection of Wolbachia and S. glossinidius}

Of the 184 midguts that were simultaneous analyzed for the presence of Wolbachia and S. glossinidius, 10 (5.43\%) revealed co-infections with these two symbionts. Between villages, no significant difference $(P=0.0957)$ was observed in the number of tsetse flies with midguts co-infected by Wolbachia and S. glossinidius (Table 3). 
Table 2. Infection rates of $S$. glossinidius according to villages.

\begin{tabular}{lcccc}
\hline Villages & $\begin{array}{c}\text { Number of tsetse } \\
\text { flies captured }\end{array}$ & $\begin{array}{c}\text { Number of midguts } \\
\text { analyzed }\end{array}$ & $\begin{array}{c}\text { Number of midguts } \\
\text { with S. glossinidius } \\
\text { infections (\%) }\end{array}$ & $\begin{array}{c}\text { 95\% CI } \\
\text { Bakwanseke }\end{array}$ \\
Bena Mungelu & 10 & 6 & $1(16.67)$ & $0.42-64.12$ \\
Ekubi 2 & 239 & 226 & $36(15.93)$ & $11.73-21.26$ \\
Kabala & 203 & 56 & $4(7.14)$ & $1.81-16.97$ \\
Kabengele & 16 & 14 & 0 & $1.27-31.47$ \\
Lutendele & 3 & 2 & $11(22.45)$ & $13.02-35.88$ \\
Tshibila & 222 & 49 & $3(42.86)$ & $9.9-81.59$ \\
Total & 7 & 7 & $56(15.55)$ & $12.18-19.66$ \\
$P$-value & 700 & 360 & 0.2002 & \\
\hline
\end{tabular}

(\%): S. glossinidius infection rate; CI: Confidence interval.

Table 3. Wolbachia and S. glossinidius infection rates according to villages and number of tsetse with co-infections of Wolbachia and S. glossinidius.

\begin{tabular}{|c|c|c|c|c|c|c|c|c|}
\hline Villages & $\begin{array}{c}\text { Number of } \\
\text { tsetse flies } \\
\text { captured }\end{array}$ & $\begin{array}{l}\text { Number of } \\
\text { midguts } \\
\text { analyzed }\end{array}$ & $\begin{array}{l}\text { Number of } \\
\text { midguts with } \\
\text { Wolbachia } \\
\text { infections (\%) }\end{array}$ & $95 \% \mathrm{CI}$ & $\begin{array}{l}\text { Number of } \\
\text { midguts with } \\
\text { S. glossinidius } \\
\text { infections (\%) }\end{array}$ & $95 \% \mathrm{CI}$ & $\begin{array}{l}\text { Number of midguts } \\
\text { with co-infection of } \\
\text { Wolbachia and } \\
\text { S. glossinidius }(\%)\end{array}$ & $95 \% \mathrm{CI}$ \\
\hline Bakwanseke & 10 & 7 & $5(71.43)$ & $29.04-96.33$ & $0(0)$ & & $1(14.28)$ & $0.36-57.87$ \\
\hline Bena Mungelu & 239 & 114 & $111(97.37)$ & $92.55-99.10$ & $21(18.42)$ & $12.38-26.52$ & $5(4.39)$ & $1.89-9.86$ \\
\hline Ekubi 2 & 203 & 24 & $21(87.5)$ & $69-95.65$ & $4(16.67)$ & $6.68-35.85$ & $1(4.17)$ & $0.74-20.24$ \\
\hline Kabala & 16 & 11 & $11(100)$ & $74.12-100$ & $1(9.09)$ & $1.62-37.73$ & $1(9.09)$ & $1.62-37.73$ \\
\hline Kabengele & 3 & 2 & $2(100)$ & $15.81-100$ & $0(0)$ & & 0 & \\
\hline Lutendele & 222 & 20 & $0(0)$ & & $11(55)$ & $16.23-37.73$ & 0 & \\
\hline Tshibila & 7 & 6 & $6(100)$ & $54.07-100$ & $3(50)$ & $11.81-88.19$ & $2(33.33)$ & $4.33-77.72$ \\
\hline Total & 700 & 184 & $156(84.78)$ & $78.88-89.26$ & $40(21.74)$ & $16.76-28.84$ & $10(5.43)$ & $2.99-9.71$ \\
\hline$P$-value & & & 0.9967 & & 0.1018 & & 0.0957 & \\
\hline
\end{tabular}

(\%): Infection rates; CI: Confidence interval.

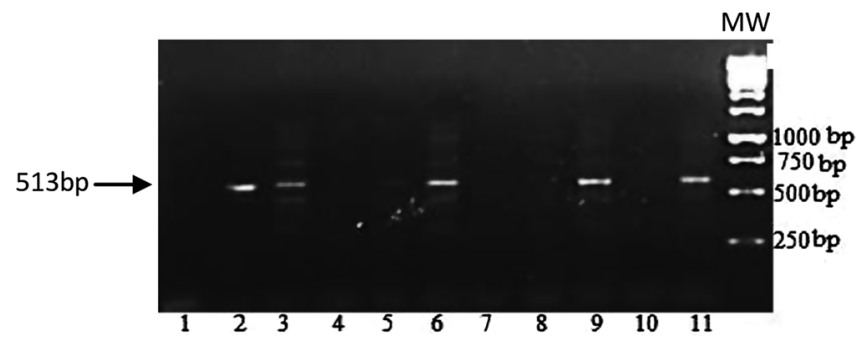

Figure 3. Agarose gel illustrating the DNA profile resulting from the amplification of a DNA fragment of the Wolbachia surface protein gene using wsp primers. MW: $1 \mathrm{~kb}$ DNA ladder molecular weight marker; lane 1: negative control; lane 11: positive control; Lane 2, 3, 6 and 9: samples positive for Wolbachia; lanes 4, 5, 7, 8 and 10: samples negative for Wolbachia.

\section{Discussion}

One of the main challenges that limits our appraisal of the tsetse microbiome is the difficulty encountered in identifying bacterial species that colonize these flies. To contribute to filling the gaps in the understanding of the bacterial flora of certain understudied tsetse species, molecular tools were used to identify $S$. glossinidius and Wolbachia in the midgut of G. f. quanzensis caught in different regions of the Democratic Republic of Congo.

Although few investigations have been undertaken on S. glossinidius in tsetse of the G. fuscipes species, the first attempts using standard PCR (amplification of specific gene by conventional PCR), and culture dependent and independent methods failed to identify $S$. glossinidius in G. f. fuscipes populations from Uganda [5] and Kenyan [33]. However, other approaches combining standard PCR and qPCR methods that target regions other than the $16 \mathrm{~S}$ rRNA gene have recently allowed for the confirmation of the presence of $S$. glossinidius in different tsetse species including $G$. $f$. fuscipes populations from Uganda [1]. Our results showing $S$. glossinidius in G. $f$. quanzensis in the DRC are therefore in agreement with the results of Aksoy et al. [1] and those obtained in other tsetse flies of the palpalis and morsitans groups [13, 20]. The findings of the present study thus open a framework for investigations aimed at understanding the implications of $S$. glossinidius in the vector competence of $G$. $f$. quanzensis. Comparing the infection rates of $S$. glossinidius between wild populations of different tsetse species of various regions, our infection rate of $15.6 \%$ is similar to $17.5 \%$ reported in Zambia for G. $m$. morsitans [13]. This rate is higher than $1.4 \%$ and $9.3 \%$ 
Table 4. Amplification rates of the fbpA gene according to the villages.

\begin{tabular}{lccc}
\hline Villages & $\begin{array}{c}\text { Number of } \\
\text { midguts } \\
\text { analyzed }\end{array}$ & $\begin{array}{c}\text { Number of midguts } \\
\text { with amplified } \\
\text { fbpA gene (\%) }\end{array}$ & $95 \%$ CI \\
\hline Bakwanseke & 5 & $5(100)$ & $47.83-100$ \\
Bena Mungelu & 111 & $78(70.27)$ & $61.21-77.98$ \\
Ekubi 2 & 21 & $4(19.05)$ & $7.67-40$ \\
Kabala & 11 & $4(36.36)$ & $15.17-64.62$ \\
Kabengele & 2 & $0(0)$ & \\
Tshibila & 6 & $2(33.33)$ & $4.33-77.72$ \\
Total & 156 & $93(59.61)$ & $51.77-66.99$ \\
$P$-value & & 0.1062 & \\
\hline
\end{tabular}

(\%): Rate of midguts with amplified fbpA gene; CI: Confidence interval.

reported for G. pallidipes in Zambia [13] and G. p. palpalis in Liberia [34], but lower than $93.7 \%$ and $54.9 \%$ reported in Zambia for G. brevipalpis [13], and in Cameroon for G. p. palpalis [20]. However, in the present study, it is important to point out that $S$. glossinidius was identified in tsetse midguts, while other studies used whole tsetse or parts of the insect such as the abdomen, the thorax and the legs. Although these methodological variations have important implications in the comparison of data resulting from different studies, the results generated by these studies confirm the high heterogeneity of $S$. glossinidius infection rates according to tsetse species $[13,20]$.

The variations observed in the infection rates (7.14-22.45\%) of $S$. glossinidius according to the villages corroborate results obtained in G. p. palpalis of two HAT foci of southern Cameroon [20]. They are in agreement with results reported in Kenyan populations of $G$. austeni and G. pallidipes where some variations were observed in $S$. glossinidius infection rates according to sampling sites [45]. These variations can be explained by the bacterial density as well as environmental factors (vegetation, humidity, temperature) that differ between villages [45]. The difference in the bacterial diversities could reflect various abiotic factors, such as humidity and wetlands which play a role in environmental exposure of tsetse and its symbiotic microorganisms. In experimental studies where environmental variations are removed and the symbiotic association between tsetse and symbionts is not affected, high vertical transmission of symbionts is observed and high infection rates are expected. The submission of different tsetse populations to constant and specific environmental conditions has probably induced selection of specific tsetse populations characterized by high vertical transmission of $S$. glossinidius. However, in natural conditions where bioclimatic factors vary and have impacts on tsetse biology, the relationship between tsetse and symbionts can be modified. As the survival of symbionts is linked to tsetse biology because of their limited metabolic capacities, each environmental modification affecting the biology of tsetse modifies the molecular interactions between tsetse and symbionts. In such a context, $S$. glossinidius could not easily undergo horizontal transmission and its infection rates could vary with environmental factors.
The identification of Wolbachia in G. $f$. quanzensis contrasts with the results of first attempts where no such infection was reported in some tsetse of the fuscipes species [10, 16]. However, our results are in line with those of Symula et al. [43] who reported Wolbachia in G.f. fuscipes. The discrepancy between these results can be linked to the variety of tsetse species, the sensitivity of molecular markers and the density of Wolbachia in different tsetse species. Indeed, with molecular markers targeting Wolbachia surface protein (wsp-PCR), Schneider et al. [42] categorized Wolbachia infections into high, intermediate, low and not detectable in G. m. centralis, G. m. morsitans, G. swynnertoni, and G. brevipalpis, respectively. The same authors applied the PCR-blot technique and significantly enhanced the detection capacity of Wolbachia in different tsetse species. Interestingly, this PCR-blot technique made it possible to detect Wolbachia in samples of some tsetse species such as $G$. swynnertoni that were previously reported with no infection [42], indicating clearly that $G$. swynnertoni can host Wolbachia. These results show some variations in the sensitivity of techniques and molecular markers used to detect symbionts. They also show some variability in the density of Wolbachia according to tsetse species. These factors have impacts on the Wolbachia infection rates and highlight the need to develop sensitive tools for a real evaluation of Wolbachia infection in different tsetse species.

Our infection rate of $84.8 \%$ is lower than the $100 \%$ reported in G. austeni [45]. This discrepancy can be linked to tsetse species because each of them is characterized by specific molecular interactions with its symbiotic microorganisms. These interactions have impacts on the density of Wolbachia and subsequently, on its infection rate. The infection rate of $84.8 \%$ reported here does not reflect the real prevalence of Wolbachia in G. $f$. quanzensis because only midguts were investigated. With such focused investigations, the real prevalence of Wolbachia was probably underestimated because Wolbachia can be found in other parts such as the head, thorax, abdomen and legs [45]. Some of the $15.2 \%$ midguts reported with no infection could come from insects that harbor Wolbachia in other tissues not considered in this study. Some of these midguts may host low Wolbachia density below the detection threshold of the markers used. The heterogeneity observed in Wolbachia infection rates according to villages is in agreement with the observations of Cheng et al. [10], reporting significant variability in wild tsetse populations. In field conditions, bioclimatic factors affect the symbiotic association between tsetse and its symbionts, and consequently the infection rates of symbiotic microorganisms [16, 40].

The midgut infection by Wolbachia contrasts with previous observations reporting the main localization of Wolbachia in tsetse fly ovaries. Our results are in agreement with those of Wamwiri et al. [45] who used similar approaches to detect Wolbachia in the head, thorax, abdomen and legs of G. austeni. Although Wamwiri et al. [45] found Wolbachia in the abdomen (probably containing midgut and ovary) of the tsetse fly, the results of their study and those generated here show that Wolbachia is not just confined to gonads, but could colonize other tsetse tissues. The presence of Wolbachia in other tissues could result from specific Wolbachia strains probably with large tissue tropism in some tsetse species as reported in other 
insects [14]. For instance, Wolbachia has been detected in ovary and non-gonadal tissues of Culex quinquefasciatus, with high density in ovaries compared to non-gonadal tissues [19]. As in $C$. quinquefasciatus, the density of Wolbachia could also vary according to tsetse tissues. If Wolbachia density is high in ovaries compared to other tissues like tsetse midguts, we can therefore understand why these bacteria have never been detected in such tissues. This hypothesis is strengthened by the observations of Wamwiri et al. [45] who found differences in the intensity of PCR products of Wolbachia specific fragments between Kenyan and the South African tsetse populations. The Wolbachia strains found in the tsetse midgut may have specific characters like large tissue tropism and invasion capacity that are probably different from those of strains previously studied. Such tissue tropism has already been reported in other tsetse species such as G. auteni [10]. Genetic investigations on these strains could help to decrypt and understand the differences observed. Moreover, in the current elimination context of Human African trypanosomiases, the identification of Wolbachia in tsetse midgut opens a framework for investigations intended to develop paratransgenic approaches for vectorcontrol. If Wolbachia prevent trypanosome infections, the presence of specific strains in tsetse midgut could open new perspectives for vector control where trypanosomes establishment could be prevented. Although the prevention mechanism is not yet understood, recent investigations highlight a negative correlation between Wolbachia and the presence of trypanosomes [2, 5]. Similar observations have already been described in other vector-borne diseases. In mosquitoes for instance, Wolbachia has been reported to confer resistance against Plasmodium and dengue virus through the stimulating the expression of certain genes related to the host's immune response $[8,30]$. Assuming the presence of Wolbachia in tsetse midgut, we can speculate that its direct contact with trypanosomes could prevent the establishment of this parasite, possibly due to interaction with the host and a subsequent impact on the host immune response, rather than direct contact with the trypanosome. Decrypting Wolbachia-tsetsetrypanosome interactions for the final goal of understanding how Wolbachia could prevent trypanosome establishment requires additional investigations.

Of the five genes ( $f b p A, h c p A$, gat $B, \operatorname{cox} A$ and $f t s Z)$ selected for MLST, only $f b p A$ was amplified in about $60 \%$ of Wolbachia positive samples. The amplification, sequencing and comparison of fbpA sequences with those available in the database showed that the amplified sequences belonged to Wolbachia, thus confirming its presence in the tsetse midgut. For the other genes, no amplification was observed. These results could be explained by the low titer of Wolbachia that could be below the detection threshold of "standard" PCR (amplification of a specific gene by conventional PCR). In fact, Schneider et al. [42] have shown some Wolbachia strains escaping the "standard" PCR methods by hiding as low titer below the detection threshold. Applying a highly sensitive PCR-blot technique to the same samples, these authors observed a high prevalence of Wolbachia infections, even in tsetse species initially found with no infection. In addition, Wolbachia genomes can undergo frequent rearrangements and rapid evolution due to the high number of transposable elements and repeat regions that provide sites for recombination $[9,22,31]$. As reported in other bacteria $[9,17,38]$, these permanent genetic modifications could lead to mutations at the primer binding sites.

This study showed that only $5.43 \%$ of $G$. $f$. quanzensis midguts were co-infected by Wolbachia and $S$. glossinidius. This result indicates that the midguts of natural populations of G. f. quanzensis are rarely coinfected by Wolbachia and S. glossinidius. This low midgut co-infection of Wolbachia and $S$. glossinidius can be linked to the differences observed in the biological effects of these bacteria. The presence of trypanosomes was reported to be negatively correlated $(r=-0.176)$ with Wolbachia infection, suggesting that infection by Wolbachia may prevent trypanosome infections $[2,5]$. On the contrary, the presence of $S$. glossinidius seems to favor trypanosome infections [20]. These observations indicate that some antagonistic actions resulting from the biological effects of Wolbachia and S. glossinidius may occur in tsetse midgut during trypanosome infections. They also indicate difficult co-association between S. glossinidius and Wolbachia in the tsetse midgut. The low prevalence of co-infections between S. glossinidius and Wolbachia is probably underestimated because only tsetse midguts were analyzed. Since S. glossinidius and Wolbachia can be found in other tissues not analyzed here, investigations of such tissues could increase the co-infection rates of these bacteria. A better understanding of the association between these bacteria by continuing investigations on the infection rates of both Wolbachia and S. glossinidius could help to develop new vector control strategies. For example, sustained elimination of HAT could be achieved over 25 years when Wolbachia colonization minimally impacted fecundity or mortality, and when the probability of recombinant Sodalis vertical transmission exceeded $99.9 \%$ [25].

\section{Conclusion}

This study revealed Wolbachia and S. glossinidius in G. f. quanzensis for the first time. The infection rates of these bacteria vary between villages due to climatic and environmental factors. Our results showed that few tsetse flies harbor midgut co-infections of Wolbachia and S. glossinidius. The data generated in this study have improved our knowledge of the bacterial flora of G. $f$. quanzensis and opened a framework for investigations aimed at understanding the implication of these symbiotic microorganisms in the vectorial competence of G. f. quanzensis. In the elimination context where control strategies have to be improved, more data on the simultaneous presence of Wolbachia and S. glossinidius could help to develop new approaches for vector control.

Acknowledgements. This work was supported by the University of Yaoundé I and University of Dschang, Cameroon.

\section{Competing interests}

The authors declare that they have no competing interests. 


\section{Supplementary material}

Supplementary materials are available at https://www. parasite-journal.org/10.1051/parasite/2019005/olm.

\section{References}

1. Aksoy E, Telleria EL, Echodu R, Wu Y, Okedi LM, Weiss BL, Aksoy S, Caccone A. 2014. Analysis of multiple tsetse fly populations in Uganda reveals limited diversity and speciesspecific gut microbiota. Applied and Environmental Microbiology, 80, 4301-4312.

2. Aksoy S, Caccone A, Galvani AP, Okedi LM. 2013. Glossina fuscipes populations provide insights for Human African Trypanosomiasis transmission in Uganda. Trends in Parasitology, 29, 394-406.

3. Aksoy S. 2003. Control of tsetse flies and trypanosomes using molecular genetics. Veterinary Parasitology, 115, 125-145.

4. Aksoy S. 2000. Tsetse a haven for microorganisms. Parasitology Today, 16, 114-118.

5. Alam U, Hyseni C, Symula R, Brelsfoard C, Wu Y, Kruglov O, Wang J, Echodu R, Alioni V, Okedi LM, Caccone A, Aksoy S. 2012. Implications of microfauna-host interactions for trypanosome transmission dynamics in Glossina fuscipes fuscipes in Uganda. Applied and Environmental Microbiology, 78, 4627.

6. Alam U, Medlock J, Brelsfoard C, Pais R, Lohs C, Balmand S, Carnogursky J, Heddi A, Takac P, Galvani A, Aksoy S. 2011. Wolbachia symbiont infections induce strong cytoplasmic incompatibility in the Tsetse Fly Glossina morsitans. PLoS Pathogens, 7(12), e1002415.

7. Baldo L, Hotopp JCD, Jolley KA, Bordenstein SR, Biber SA, Choudhury RR, Hayashi C, Maiden MCJ, Tettelin H, Werren JH. 2006. Multilocus sequence typing system for the endosymbiont Wolbachia pipientis. Applied and Environmental Microbiology, 72, 7098-7110.

8. Bian G, Xu Y, Lu P, Xie Y, Xi Z. 2010. The endosymbiotic bacterium Wolbachia induces resistance to dengue virus in Aedes aegypti. PLoS Pathogens, 6(4), e1000833.

9. Brownlie JC, O’Neill SL. 2005. Wolbachia genomes: insights into an intracellular lifestyle. Current Biology, 15, R507-509.

10. Cheng Q, Ruel TD, Zhou W, Moloo SK, Majiwa P, O’Neill SL, Aksoy S. 2000. Tissue distribution and prevalence of Wolbachia infections in tsetse flies, Glossina spp. Medical and Veterinary Entomology, 14, 44-50.

11. Dale C, Welburn SC. 2001. The endosymbionts of tsetse flies: manipulating host-parasite interactions. International Journal for Parasitology, 31, 628-631.

12. Darby AC, Lagnel J, Matthew CZ, Bourtzis K, Maudlin I, Welburn SC. 2005. Extrachromosomal DNA of the symbiont Sodalis glossinidius. Journal of Bacteriology, 187, 5003-5007.

13. Dennis JW, Durkin SM, Horsley DJE, Hamill LC, Anderson NE, MacLeod ET. 2014. Sodalis glossinidius prevalence and trypanosome presence in tsetse from Luambe National Park, Zambia. Parasites and Vectors, 7, 378.

14. Dobson SL, Bourtzis K, Braig HR, Jones BF, Zhou W, Rousset F, O'Neil SL. 1999. Wolbachia infections are distributed throughout insect somatic and germ line tissues. Insect Biochemistry and Molecular Biology, 29, 153-160.

15. Doudoumis V, Blow F, Saridaki A, Augustinos A, Dyer NA, Goodhead I, Solano P, Rayaisse J-B, Takac P, Mekonnen S, Parker AG, Abd-Alla AMM, Darby A, Bourtzis K, Tsiamis G. 2017. Challenging the Wigglesworthia, Sodalis, Wolbachia symbiosis dogma in tsetse flies: Spiroplasma is present in both laboratory and natural populations. Scientific Reports, 7, 4699.
16. Doudoumis V, Tsiamis G, Wamwiri F, Brelsfoard C, Alam U, Aksoy E, Dalaperas S, Abd-Alla A, Ouma J, Takac P, Aksoy S, Bourtzis K. 2012. Detection and characterization of Wolbachia infections in laboratory and natural populations of different species of tsetse flies (genus Glossina). BMC Microbiology, 12, $1-13$.

17. Duron O. 2013. Lateral transfers of insertion sequences between Wolbachia, Cardinium and Rickettsia bacterial endosymbionts. Heredity, 111, 330-337.

18. Dyer AN, Ravel S, Choi K-S, Darby CA, Causse S, Kapitano B, Hall MJR, Steen K, Lutumba P, Madinga J, Torr SJ, Okedi LM, Lehane MJ, Donnelly MJ. 2011. Cryptic diversity within the major trypanosomiasis vector Glossina fuscipes revealed by molecular markers. PLoS Neglected Tropical Diseases, 5(8), 12.

19. Emerson KJ, Glaser RL. 2017. Cytonuclear epistasis controls the density of symbiont Wolbachia pipientis in non-gonadal tissues of mosquito Culex quinquefasciatus. G3: Genes/ Genomes/Genetics (Bethesda), 7, 2627-2635.

20. Farikou O, Njiokou F, Mbida Mbida JA, Njitchouang GR, Djeunga HN, Asonganyi T, Simarro P, Cuny G, Geiger A. 2010. Tripartite interactions between tsetse flies, Sodalis glossinidius and trypanosomes. An epidemiological approach in two historical human African trypanosomiasis foci in Cameroon. Infection, Genetics and Evolution, 10, 115-121.

21. Fèvre ME, Martin O, Paul GC, Mark EJW, Susan Welburn SC. 2008. Estimating the burden of rhodesiense sleeping sickness during an outbreak in Serere, eastern Uganda. BMC Public Health, 8, 96.

22. Foster JM, Raverdy S, Ganatra MB, Colussi PA, Taron CH, Carlow CK. 2009. The Wolbachia endosymbiont of Brugia malayi has an active phosphoglycerate mutase: a candidate target for antifilarial therapies. Parasitology Research, 104, 1047-1052.

23. Geiger A, Ponton F, Simo G. 2015. Adult blood-feeding tsetse flies, trypanosomes, microbiota and the fluctuating environment in sub-Saharan Africa. ISME Journal, 9, 1496-1507.

24. Geiger A, Ravel S, Frutos R, Cuny G. 2005. Sodalis glossinidius (Enterobacteriaceae) and vectorial competence of Glossina palpalis gambiensis and Glossina morsitans morsitans for Trypanosoma congolense savannah type. Current Microbiology, 51, 35-40.

25. Gilbert JA, Medlock J, Townsend JP, Aksoy S, Ndeffo Mbah M, Galvani AP. 2016. Determinants of Human African Trypanosomiasis Elimination via Paratransgenesis. PLoS Neglected Tropical Diseases, 10(3), e0004465.

26. Gouteux JP, Lancien JC. 1986. The pyramidal trap for collecting and controlling tsetse flies (Dipteria: Glossinidae). Comparative trials and description of new collecting techniques. Tropical Medicine and Parasitology, 37, 61-66.

27. Grébaut P, Bena JM, Manzambi EZ, Mansinsa P, Khande V, Ollivier G, Cuny G, Simo G. 2009. Characterization of sleeping sickness transmission sites in rural and periurban areas of Kinshasa (République Démocratique du Congo). Vector Borne Zoonotic and Diseases, 9, 631-636.

28. Hoare CA. 1972. The trypanosomes of mammals, a zoological monograph. Oxford \& Edinburgh: Blackwell Scientific Publications, $17,749 \mathrm{p}$.

29. Hoffmann AA, Turelli M. 1997. Cytoplasmic incompatibility in insects, in Influential Passengers, O'Neill SL, Hoffmann AA, Werren JH, Editors. Oxford University Press: Oxford, UK. p. $42-80$.

30. Kambris Z, Blagborough AM, Pinto SB, Blagrove MSC, Godfray HCJ, Sinden RE, Sinkins SP. 2010. Wolbachia stimulates immune gene expression and inhibits Plasmodium development in Anopheles gambiae. PLoS Pathogens, 6(10), e1001143. 
31. Klasson L, Kambris Z, Cook PE, Walker T, Sinkins SP. 2009. Horizontal gene transfer between Wolbachia and the mosquito Aedes aegypti. BMC Genomics, 10, 33.

32. Laveissière C, Grébaut P, Herder S, Penchenier L. 2000. Les glossines vectrices de la Trypanosomiase humaine. Éditions IRD: Bondy, France. p. 246.

33. Lindh JM, Lehane MJ. 2011. The tsetse fly Glossina fuscipes fuscipes (Diptera: Glossina) harbours a surprising diversity of bacteria other than symbionts. Antonie van Leeuwenhoek, 99, 711-720.

34. Maudlin I, Welburn SC, Mehlitz D. 1990. The relationship between rickettsia-like-organisms and trypanosome infections in natural populations of tsetse in Liberia. Tropical Medicine and Parasitology, 41, 265-267.

35. Morgulis A, Coulouris G, Raytselis Y, Madden TL, Agarwala R, Schäffer AA. 2008. Database indexing for production MegaBLAST searches. Bioinformatics, 24, 1757-1764.

36. Navajas M, Lagnel J, Gutierrez J, Bourset P. 1998. Species wide homogeneity of nuclear ribosomal ITS2 sequences in the spider mite Tetranychus urticae contrasts with extensive mitochondrial COI polymorphism. Heredity, 80, 742-752.

37. Pais R, Lohs C, Wu Y, Wang J, Aksoy S. 2008. The obligate mutualist Wigglesworthia glossinidia influences reproduction, digestion, and immunity processes of its host, the tsetse fly. Applied and Environmental Microbiology, 74, 5965-5974.

38. Parkhill J, Sebaihia M, Preston A, Murphy LD, Thomson N, Harris DE, Holden MTG, Churcher CM, Bentley SD, Mungall KL, Cerdeño-Tárraga AM, Temple L, James K, Harris B, Quail MA, Achtman M, Atkin R, Baker S, Basham D, Bason N, Cherevach I, Chillingworth T, Collins M, Cronin A, Davis P, Doggett J, Feltwell T, Goble A, Hamlin N, Hauser H, Holroyd S, Jagels K, Leather S, Moule S, Norberczak H, O'Neil S, Ormond D, Price C, Rabbinowitsch E, Rutter S, Sanders M, Saunders D, Seeger K, Sharp S, Simmonds M, Skelton J, Squares R, Squares S, Stevens K, Unwin L, Whitehead S, Barrell BG, Maskell DJ. 2003. Comparative analysis of the genome sequences of Bordetella pertussis, Bordetella parapertussis and Bordetella bronchiseptica. Nature Genetics, 35, 32-40.

39. R Core Team. 2018. R: A language and environment for statistical computing. R Foundation for Statistical Computing: Vienna, Austria. https://www.R-project.org.
40. Rio RVM, Yi-neng W, Filardo G, Aksoy S. 2006. Dynamics of multiple symbiont density regulation during host development: tsetse fly and its microbial flora. Proceedings of the Royal Society of London. Series B: Biological Sciences, 273, 805-814.

41. Rio RVM, Youjia H, Aksoy S. 2004. Strategies of the hometeam: symbiose exploited for vector-borne disease control. Trends in Microbiology, 12, 7 pp.

42. Schneider DI, Kathrin IG, Andrew GP, Adly MM, Abd-Alla Wolfgang JM. 2013. Global Wolbachia prevalence, titer fluctuations and their potential of causing cytoplasmic incompatibilities in tsetse flies and hybrids of Glossina morsitans subgroup species. Journal of Invertebrate Pathology, 112, S104-S115.

43. Symula ER, Alam U, Brelsfoard C, Wu Y, Echodu R, Okedi LM, Aksoy S, Caccone A. 2013. Wolbachia association with the tsetse fly, Glossina fuscipes fuscipes, reveals high levels of genetic diversity and complex evolutionary dynamics. BMC Evolutionary Biology, 13, 31.

44. Vreysen MJ, Saleh KM, Ali MY, Abdulla AM, Zhu ZR, Juma KG, Dyck VA, Msangi AR, Mkonyi PA, Feldmann HU. 2000. Glossina austeni (Diptera: Glossinidae) eradicated on the island of Unguja, Zanzibar, using the sterile insect technique. Journal of Economic Entomology, 93(1), 123-135.

45. Wamwiri NF, Alam U, Thande CP, Aksoy E, Ngure MR, Aksoy S, Ouma OJ, Murilla AG. 2013. Wolbachia, Sodalis and trypanosome co-infections in natural populations of Glossina austeni and Glossina pallidipes. Parasites and Vectors, 6, 232.

46. Weiss B, Aksoy S. 2011. Microbiome influences on insect host vector competence. Trends in Parasitology, 11, 514-522.

47. Welburn SC, Maudlin I, Simarro PP. 2009. Controlling sleeping sickness - a review. Parasitology, 136, 1943-1949.

48. Welburn SC, Maudlin I. 1999. Tsetse-trypanosome interactions: rites of passage. Parasitology Today, 15, 399-403.

49. WHO. 2012. Accelerating work to overcome neglected tropical diseases: a roadmap for implementation. World Health Organization: Geneva, Switzerland.

50. Zheng Z, Scott S, Lukas W, Webb M. 2000. A greedy algorithm for aligning DNA sequences. Journal of Computational Biology, 7, 203-214.

Cite this article as: Simo G, Kanté ST, Madinga J, Kame G, Farikou O, Ilombe G, Geiger A, Lutumba P \& Njiokou F. 2019. Molecular identification of Wolbachia and Sodalis glossinidius in the midgut of Glossina fuscipes quanzensis from the Democratic Republic of Congo. Parasite 26, 5 .

Reviews, articles and short notes may be submitted. Fields include, but are not limited to: general, medical and veterinary parasitology; morphology, including ultrastructure; parasite systematics, including entomology, acarology, helminthology and protistology, and molecular analyses; molecular biology and biochemistry; immunology of parasitic diseases; host-parasite relationships; ecology and life history of parasites; epidemiology; therapeutics; new diagnostic tools.

All papers in Parasite are published in English. Manuscripts should have a broad interest and must not have been published or submitted elsewhere. No limit is imposed on the length of manuscripts.

Parasite (open-access) continues Parasite (print and online editions, 1994-2012) and Annales de Parasitologie Humaine et Comparée (1923-1993) and is the official journal of the Société Française de Parasitologie. 